\title{
Association between cervical dysplasia and female genital schistosomiasis diagnosed by genital PCR in Zambian women
}

H. Rafferty ${ }^{1}$, A. S. Sturt ${ }^{1}$, C. R. Phiri ${ }^{2}$, E. L. Webb ${ }^{3}$, M. Mudenda ${ }^{4}$, J. Mapani ${ }^{4}$, P. L. A. M. Corstjens ${ }^{5}$, G. J. van Dam ${ }^{6}$ A. Schaap ${ }^{2}$, H. Ayles ${ }^{1,2}$, R. J. Hayes ${ }^{3}$, L. van Lieshout ${ }^{6}$, I. Hansingo $^{4}$ and A. L. Bustinduy ${ }^{1 *}$

\begin{abstract}
Background: Female genital schistosomiasis (FGS) is a neglected tropical gynaecological disease that affects millions of women in sub-Saharan Africa (SSA). FGS is caused by Schistosoma haematobium, a parasitic carcinogen involved in the pathogenesis of squamous cell carcinoma of the bladder. Cervical cancer incidence and mortality are highest in SSA, where pre-cancerous cervical dysplasia is often detected on screening with visual inspection with acetic acid (VIA). There are no studies evaluating the association between VIA positivity and FGS diagnosed by genital PCR.

Methods: Women were recruited from the Bilharzia and HIV (BILHIV) study in Zambia a community-based study comparing genital self-sampling to provider obtained cervicovaginal-lavage for the diagnosis of FGS in women aged 18-31. FGS was defined as positive Schistosoma DNA from any genital PCR. Urogenital schistosomiasis diagnostics included urine circulating anodic antigen, urine microscopy and portable colposcopy. Participants were offered cervical cancer screening using VIA at Livingstone Central Hospital. Associations of PCR confirmed FGS and other diagnostics with VIA positivity were assessed using multivariable logistic regression.

Results: VIA results were available from 237 BILHIV participants. A positive Schistosoma PCR in any genital specimen was detected in 14 women (5.9\%), 28.6\% (4/14) of these women had positive VIA compared to $9.0 \%$ without PCR evidence of schistosome infection (20/223). Schistosoma PCR positivity in any genital specimen was strongly associated with VIA positivity (OR: 6.08, 95\% Cl: 1.58-23.37, $P=0.02$ ).
\end{abstract}

Conclusions: This is the first study to find an association between FGS and positive VIA, a relationship that may be causal. Further longitudinal studies are needed.

Keywords: Female genital schistosomiasis, Cervical dysplasia, Schistosoma haematobium, PCR, Urogenital schistosomiasis

\footnotetext{
* Correspondence: Amaya.Bustinduy@lshtm.ac.uk

'Department of Clinical Research, London School of Hygiene and Tropical Medicine, Keppel Street, London WC1E 7HT, UK

Full list of author information is available at the end of the article
}

(c) The Author(s). 2021 Open Access This article is licensed under a Creative Commons Attribution 4.0 International License, which permits use, sharing, adaptation, distribution and reproduction in any medium or format, as long as you give appropriate credit to the original author(s) and the source, provide a link to the Creative Commons licence, and indicate if changes were made. The images or other third party material in this article are included in the article's Creative Commons licence, unless indicated otherwise in a credit line to the material. If material is not included in the article's Creative Commons licence and your intended use is not permitted by statutory regulation or exceeds the permitted use, you will need to obtain permission directly from the copyright holder. To view a copy of this licence, visit http://creativecommons.org/licenses/by/4.0/. The Creative Commons Public Domain Dedication waiver (http://creativecommons.org/publicdomain/zero/1.0/) applies to the data made available in this article, unless otherwise stated in a credit line to the data. 


\section{Introduction}

Female genital schistosomiasis (FGS) is a neglected parasitic gynaecological disease that affects an estimated 56 million women in sub-Saharan Africa [1, 2]. It is most commonly caused by Schistosoma haematobium, blood flukes which lay eggs in the vesical plexus [2]. These eggs become entrapped in the urogenital mucosa resulting in inflammation and reproductive morbidity [3]. Cervical cancer is a leading cause of cancer-related deaths in African women [4-6]. In Zambia age-standardised incidence rates of cervical cancer are 63.3 per 100,000 with a mortality rate of 41.1 per 100,000 , over 10 times that of the United States of America [4]. S. haematobium infection causes squamous cell carcinoma (SCC) of the bladder, therefore a role in cervical cancer pathogenesis is plausible [7]. This is a prescient prospect given the recent launch by WHO of a global initiative to eliminate cervical cancer by 2030 [8].

In the absence of a reference standard, making an FGS diagnosis can be challenging and often requires the use of multiple diagnostic modalities. FGS is associated with typical genital mucosal visible lesions, however parasite eggs can be found in macroscopically normal tissue [9, 10]. Sandy patches (grainy and homogenous) and abnormal blood vessels have been associated with $S$. haematobium eggs on pap smear [11]. Cervicovaginal lavage (CVL) or genital swabs can be used to detect Schistosoma DNA by PCR [12, 13]. Community-based approaches have shown that FGS diagnosis using selfcollected cervical and vaginal swabs is acceptable to participants, has comparable sensitivity to CVL [12], and provides an objective alternative to imaging [14]. Urine microscopy for eggs or the detection of circulating anodic antigen (CAA) can diagnose active schistosome infection, but do not necessarily reflect genital involvement $[12,15]$.

Pre-cancerous stages of cervical cancer are treatable and can be detected with screening [16]. Human papillomavirus (HPV) testing is WHO-recommended for cervical screening as HPV infection is the most common cause of cervical cancer [17]. In resource-constrained settings where HPV testing is available, visual inspection with acetic acid (VIA) can be used to visualise precancerous lesions [18]. In a large meta-analysis of 32 studies, including 18 in low and middle income countries, VIA was found to be less sensitive (0.69 vs. 0.95), but more specific ( 0.87 vs. 0.84$)$ than HPV testing for the detection of cervical in situ neoplasia grade $2-3$ as diagnosed by colposcopy with or without biopsy [19]. Identified lesions are treated with cryotherapy or loop electrosurgical excision procedure (LEEP). The coexistence of FGS and cervical malignancy is welldocumented in pathology reports [20, 21], and homogenous sandy patches have been associated with the presence of high risk HPV [22]; however, this association is not universally reported [23]. This study aimed to evaluate the association between FGS and cervical dysplasia diagnosed by VIA in Zambian women.

\section{Materials and methods}

This study was a community based cross-sectional study. Data previously collected for the bilharzia and HIV study (BILHIV) and stored in clinical records were analysed retrospectively.

\section{Participant recruitment}

Between January and August 2018, 18-31 year-old, nonpregnant, sexually active participants in two schistosomiasis low-endemic communities in Zambia were consecutively recruited after the 36-month HPTN 071 (PopART) study visit to the bilharzia and HIV (BILHIV) study [12, 24].

Following informed consent, BILHIV study participants self-collected a urine sample, and cervical and vaginal swabs, as previously described [12]. During clinic follow-up at the cervical cancer clinic at Livingstone Central Hospital, midwives performed CVL and portable colposcopy (MobileODT, Tel Aviv, Israel) to capture images of vagina and cervix [12].

Cervicovaginal images were evaluated by one medically trained reviewer and classified as suggestive of 'visual FGS' if homogenous sandy patches, grainy sandy patches, rubbery papules, or abnormal blood vessels were present, and negative if none were present [25]. Women with evidence of schistosome infection by any diagnostic, or by midwife's clinical examination [25] were treated with $40 \mathrm{mg} / \mathrm{kg}$ praziquantel as recommended by WHO [25]. Participants with suspected sexually transmitted infections (STI) were offered syndromic management, as per Ministry of Health guidelines [26]. Routine STI testing was not performed at the point-ofcare in this study. Laboratory-based fourth-generation HIV-1 testing (Abbott Architect HIV Ag/Ab Combo Assay, Wiesbaden, Germany) was performed for HPTN 071 (PopART) participants at each study visit [24].

\section{Visual inspection with acetic acid}

Due to high community HIV prevalence [27], all women regardless of age, are routinely offered cervical cancer screening with VIA at the Cervical Cancer Clinic (CCC), in Livingstone Central Hospital by the Zambian Health Service. For those women that wished to be screened for cervical cancer and after CVL was obtained for the BILHIV study, 3-5\% acetic acid was applied to the cervix. An opaque white reaction was classified as positive and no change was negative [18]. VIA results were documented in the clinical records at the CCC and were not collected as part of BILHIV. In line with national and 
local clinic protocols adapted to real-world resource limitations, HPV testing was not performed. Later, data matching was performed to identify BILHIV participants that had also attended the CCC for cervical cancer screening. All BILHIV participants with an available VIA result from routine Zambia Health Service screening were included if data could be matched from both sources.

\section{Schistosoma diagnostics}

DNA isolation was performed at Leiden University Medical Center (LUMC), followed by real time-PCR for the detection of Schistosoma DNA, as previously described $[12,28,29]$. CAA quantification was performed using an up-converting reporter particle lateral flow assay (UCPLF) at LUMC [30]. Analysing the equivalent of $417 \mu \mathrm{L}$ urine, a CAA value of $>0.6 \mathrm{pg} / \mathrm{mL}$ was considered positive based on a series of negative controls (highest value plus 2 SDs) [30].

This study involved retrospective analysis of data collected for previously published work from the BILHIV study [12]. VIA data were collected from existing clinical records. No additional participant participation was required.

\section{Ethics}

Ethical approval was granted by London School of Hygiene and Tropical Medicine (LSHTM) (reference 16, 451) and University of Zambia Biomedical Research Ethics Committee (reference: 011-08-17). The Livingstone Central Hospital Superintendent gave permission to conduct the study.

\section{Statistical methods}

Cervical dysplasia diagnosed by VIA was the dependent variable. Univariable logistic regression analysis was carried out to calculate crude odds ratios for associations between VIA and all exposure variables; multivariable logistic regression analysis was used to calculate adjusted odds ratios for associations between VIA and FGS variables controlling for age category and HIV status as a priori confounders. No further potential confounders could be included due to the small number of women with positive VIA. $P$-values were generated using likelihood ratio tests. All data were analysed using STATA 15 [31].

\section{Results}

A total of 237/527 (44.9\%) women from the BILHIV study also had VIA results available and were included in the analysis (see Fig. 1).

The median age was 24 (IQR 22-27) and the majority had some secondary education and were not currently employed. All 24 women (10.1\%) with positive VIA (Table 1) were treated; 20 with cryotherapy $(83.3 \%)$ and

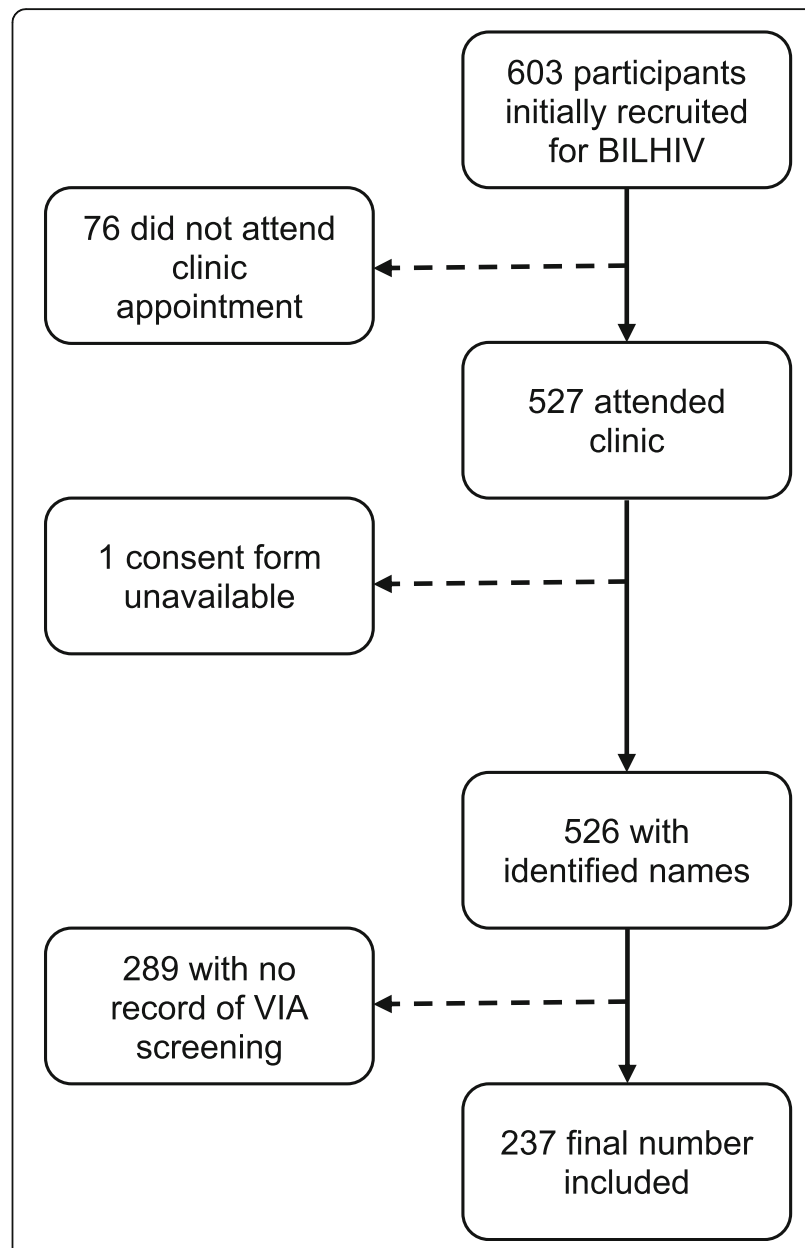

Fig. 1 Participant recruitment of 237 women in the BILHIV study who underwent VIA

4 with LEEP (16.7\%). There was no association between any demographic factors and VIA positivity (Table 2).

The prevalence of active $S$. haematobium infection was $6.3 \%(15 / 237)$ by urine microscopy, and $14.8 \%$ (35/ 237) by urine CAA (Table 1). Schistosoma PCR in any genital specimen (CVL, cervical or vaginal swab) was positive in 14/237 (5.9\%). Relative proportions for each FGS diagnostic being positive compared to all others are represented in sup. Table 1. Colposcopy images were interpretable in 216 women, of whom 70 had 'visual FGS' (29.5\%). HIV-1 prevalence was $23.8 \%(56 / 235)$.

Of 14 women with positive Schistosoma PCR, 4 were VIA positive (28.6\%), compared to 20 of 223 with negative PCR $(9.0 \%)$. The adjusted odds ratio for the association between positive VIA and FGS diagnosed by genital PCR was 6.08 (95\% CI: $1.58-23.37)$ and there was strong evidence for this association $(P=0.016)$. There was no evidence for an association between VIA positivity and 'visual FGS' (OR: 0.58, 95\% CI: 0.20-1.69, $P=0.30)$ or urine CAA/microscopy (OR 2.21, 95\% CI $0.83-5.89, P=0.13$ ) (see Fig. 2). There was only one 
Table 1 Baseline characteristics and diagnostic test results amongst 237 participant women

\begin{tabular}{|c|c|c|}
\hline \multicolumn{2}{|l|}{ Characteristics } & \multirow[t]{2}{*}{ n (\%) } \\
\hline Demography & & \\
\hline \multirow[t]{3}{*}{ Age (years) } & $18-22$ & $64(27.0)$ \\
\hline & $23-26$ & $91(38.4)$ \\
\hline & $27-31$ & $82(34.6)$ \\
\hline \multirow[t]{2}{*}{ Education } & None or primary & $74(31.2)$ \\
\hline & Secondary or higher & $163(68.8)$ \\
\hline \multirow[t]{2}{*}{ Employment } & Unemployed & $163(68.8)$ \\
\hline & Employed & $74(31.2)$ \\
\hline \multirow[t]{2}{*}{ Marital status } & Currently single & $116(49.0)$ \\
\hline & Currently married & $121(51.1)$ \\
\hline \multirow[t]{2}{*}{ Ever pregnant } & Never & $36(15.2)$ \\
\hline & Yes & $201(84.8)$ \\
\hline \multirow[t]{2}{*}{ Contraception } & Yes & $183(77.2)$ \\
\hline & No & $54(22.8)$ \\
\hline \multirow[t]{3}{*}{ Previous bilharzia diagnosis or treatment } & Yes & $29(12.2)$ \\
\hline & Unsure & $10(4.2)$ \\
\hline & No & $198(83.5)$ \\
\hline \multicolumn{3}{|l|}{ HIV } \\
\hline \multirow[t]{2}{*}{ HIV status*** } & Positive & $56(23.8)$ \\
\hline & Negative & $179(76.2)$ \\
\hline \multirow[t]{2}{*}{ HIV status self-reported**** } & Positive & $42(17.8)$ \\
\hline & Negative & $194(82.2)$ \\
\hline \multirow[t]{2}{*}{ HIV seroconversion during HPTN 071 *** } & Yes & $5(2.1)$ \\
\hline & No & $230(97.9)$ \\
\hline \multicolumn{3}{|l|}{ Cervical dysplasia } \\
\hline \multirow[t]{2}{*}{ VIA } & Positive & $24(10.1)$ \\
\hline & Negative & $213(89.9)$ \\
\hline \multirow[t]{4}{*}{ Treatment } & No treatment & $208(87.8)$ \\
\hline & Cryotherapy & $20(8.4)$ \\
\hline & LEEP & $4(1.7)$ \\
\hline & Antibiotics & $5(2.1)$ \\
\hline \multicolumn{3}{|l|}{ Schistosoma diagnostics } \\
\hline \multirow[t]{2}{*}{ Genital Schistosoma PCR } & Positive & $14(5.9)$ \\
\hline & Negative & $223(94.1)$ \\
\hline \multirow[t]{2}{*}{ Imaging findings suggestive of FGS* } & Present & $70(29.5)$ \\
\hline & Absent & $146(61.6)$ \\
\hline \multirow[t]{2}{*}{$C A A^{* *}$} & Positive & $35(14.8)$ \\
\hline & Negative & $201(84.8)$ \\
\hline \multirow[t]{2}{*}{ Urine microscopy } & Positive & $15(6.3)$ \\
\hline & Negative & $222(93.7)$ \\
\hline
\end{tabular}

${ }^{*} n=216,21$ women with uninterpretable images; ${ }^{* *} n=236$, one urine vial arrived to LUMC empty; ${ }^{* * *} n=235,2$ results missing from HPTN-271 (PopART) database; ${ }^{* * *} n=236$, one woman declined to disclose status 
Table 2 Number (n) and percentage (\%) of study variables amongst the study population by VIA status

\begin{tabular}{|c|c|c|c|c|c|c|}
\hline & & n (\%) & n (\%) VIA+ & Crude OR VIA+ & $95 \% \mathrm{Cl}$ & $P$-value \\
\hline \multirow[t]{2}{*}{ FGS by PCR $n=237$} & Positive & $14(5.9)$ & $4(28.6)$ & 4.06 & $1.15-14.38$ & 0.044 \\
\hline & Negative & $223(94.1)$ & $20(9.0)$ & 1 & & \\
\hline \multirow[t]{2}{*}{ Visual FGS $n=216^{\mathrm{a}}$} & Positive & $70(29.5)$ & $5(7.1)$ & 0.63 & $0.22-1.79$ & 0.364 \\
\hline & Negative & $146(61.6)$ & $16(11.0)$ & 1 & & \\
\hline \multirow[t]{2}{*}{ CAA $n=236^{b}$} & Positive & $35(14.8)$ & $5(14.3)$ & & $0.55-4.62$ & 0.428 \\
\hline & Negative & $201(84.8)$ & $19(9.5)$ & 1 & & \\
\hline \multirow[t]{2}{*}{ Urine microscopy $n=237$} & Positive & $15(6.3)$ & $3(20.0)$ & 2.39 & $0.62-9.23$ & 0.237 \\
\hline & Negative & $222(93.7)$ & $21(9.5)$ & 1 & & \\
\hline \multirow[t]{3}{*}{ Age $n=237$} & $18-22$ & $64(27.0)$ & $5(7.8)$ & 1 & & 0.112 \\
\hline & $23-26$ & $91(38.4)$ & $6(6.6)$ & 0.83 & $0.24-2.87$ & \\
\hline & $27-31$ & $82(34.6)$ & $13(15.9)$ & 2.22 & $0.74-6.68$ & \\
\hline \multirow[t]{2}{*}{ HIV status $n=235^{c}$} & Positive & $56(23.8)$ & $8(14.3)$ & 1.7 & $0.68-4.23$ & 0.265 \\
\hline & Negative & $179(76.2)$ & $16(8.9)$ & 1 & & \\
\hline \multirow[t]{2}{*}{ District $n=237$} & Community A & $142(59.9)$ & $15(10.6)$ & 1 & & 0.785 \\
\hline & Community B & $95(40.1)$ & $9(9.5)$ & 0.89 & $0.37-2.12$ & \\
\hline \multirow[t]{2}{*}{ Education $n=237$} & None or primary & $74(31.2)$ & $11(14.9)$ & 1 & & 0.113 \\
\hline & Secondary or higher & $163(68.8)$ & $13(8.0)$ & 0.5 & $0.21-1.18$ & \\
\hline \multirow[t]{2}{*}{ Employment $n=237$} & Unemployed & $163(68.8)$ & $15(9.2)$ & 1 & & 0.490 \\
\hline & Employed & $74(31.2)$ & $9(12.2)$ & 1.37 & $0.57-3.29$ & \\
\hline \multirow[t]{2}{*}{ Marital status $n=237$} & Currently single & $116(49.0)$ & $14(12.1)$ & 1 & & 0.331 \\
\hline & Currently married & $121(51.1)$ & $10(8.3)$ & 0.66 & $0.28-1.55$ & \\
\hline \multirow[t]{2}{*}{ Ever pregnant $n=237$} & Never & $36(15.2)$ & $20(10.0)$ & 0.88 & $0.28-2.76$ & 0.834 \\
\hline & Yes & $201(84.8)$ & $4(11.1)$ & 1 & & \\
\hline \multirow[t]{2}{*}{ Contraception $n=237$} & Yes & $183(77.2)$ & $15(8.2)$ & 1 & & 0.085 \\
\hline & No & $54(22.8)$ & $9(16.7)$ & 2.24 & $0.91-5.50$ & \\
\hline \multirow[t]{2}{*}{ Condoms $n=237$} & Yes & $47(19.8)$ & $6(12.8)$ & 1.4 & $0.52-3.75$ & 0.514 \\
\hline & No & $190(80.2)$ & $18(9.5)$ & 1 & & \\
\hline \multirow[t]{3}{*}{ Previous bilharzia diagnosis or treatment $n=237$} & Yes & $29(12.2)$ & $3(10.3)$ & 1.09 & $0.30-3.94$ & 0.630 \\
\hline & Unsure & $10(4.2)$ & $2(20.0)$ & 2.36 & $0.46-12.00$ & \\
\hline & No & 198 (83.5) & $19(9.6)$ & 1 & & \\
\hline
\end{tabular}

Abbreviations: CAA Circulating anodic antigen, CI Confidence interval, FGS female genital schistosomiasis, HIV Human immunodeficiency virus, OR odds ratio, $P C R$ polymerase chain reaction, VIA Visual inspection with acetic acid

${ }^{a} 21$ with uninterpretable images; ${ }^{b}$ one urine vial arrived to LUMC empty; ${ }^{c} 2$ results missing from HPTN-271 (PopART) database

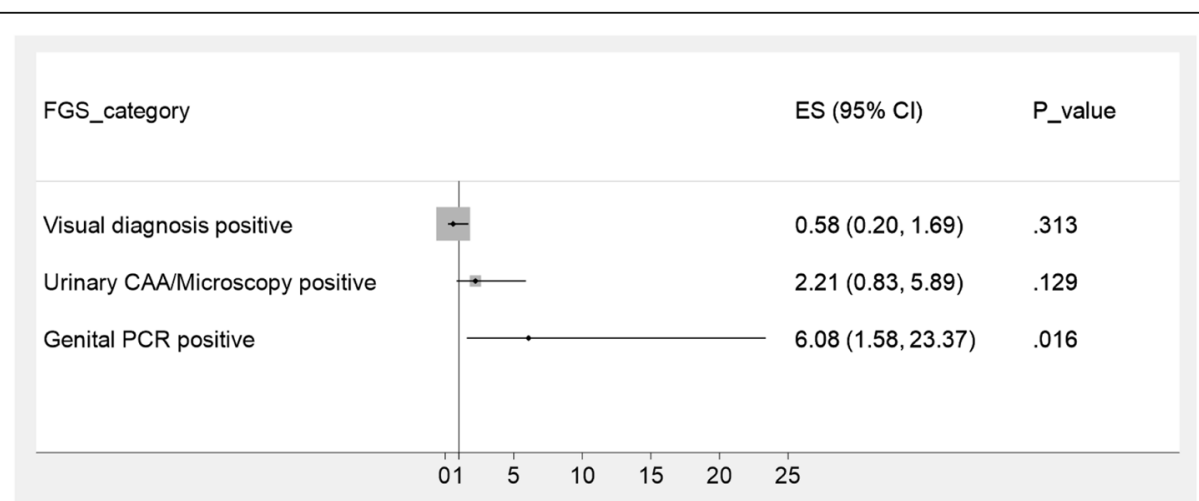

Fig. 2 Forest Plot illustrating the results of a multivariable logistic regression of different FGS diagnostic methods and positive visual inspection with acetic acid (VIA), odds ratios adjusted for age and HIV status 
woman who was both HIV-1 positive and FGS PCR positive and therefore it was not possible to perform further analysis. Of the 13 FGS positive women, 3 were HIV-negative (23.0\%), and of the 55 FGS negative women 7 were HIV positive (12.7\%).

\section{Discussion}

This study is the first to provide evidence for an association between FGS and cervical dysplasia. These are two common gynaecological conditions in SSA, which together lead to significant morbidity and mortality. Chronic inflammation due to $S$. haematobium egg deposition is thought to be on the causal pathway to bladder squamous cell carcinoma [7]. We hypothesize that the inflammatory consequences of $S$. haematobium egg deposition in FGS could similarly contribute to cervical cancer pathogenesis (Fig. 3). Possible mechanistic synergies with co-infections include FGS-related epithelial disruption [32] allowing HPV to establish infection, and the recruitment of immune cells that may influence the interaction of HIV or HPV with cervical tissue. Additionally, changes in local pro-inflammatory cytokines may promote HPV persistence or transcription [33] and a systemic Th2 environment may be associated with cervical lesion progression [34]. Alternatively, there could be confounders at the community level including access to healthcare, health education and socio-economic factors. Of note, we did not find an association between VIA and previous self-reported history of schistosomiasis. While participants may have been asymptomatic or have limited access to diagnostics, we were unable to confirm a previous diagnosis of bilharzia, and so this variable is subject to recall bias. The possible association between FGS and cervical dysplasia has important clinical implications in endemic areas where FGS is not yet considered a risk factor for cervical cancer [35]. If this association is substantiated FGS diagnosis and treatment could become an important component of cervical cancer prevention.

Several previous studies have investigated the association between $S$. haematobium and cervical dysplasia. However, heterogeneous methods in diagnosing both the exposure (FGS) and the outcome (cervical dysplasia) make cross-study comparisons challenging. In a South African study, no association was found between FGS diagnosed by CVL PCR, or pap-smear and cervical dysplasia diagnosed with cytology. However, over $97 \%$ of papsmears from women with FGS were uninterpretable, limiting the sample size [23]. A population-based crosssectional study in Zimbabwe showed an association between the presence of typical FGS homogenous yellow sandy patches and high-risk HPV [36]. After 5 years of follow-up in this cohort, sandy patches were not associated with high risk HPV persistence or cervical dysplasia but again, conclusions were limited by low power [22].

To our knowledge, VIA has not previously been used for the diagnosis of cervical dysplasia in the context of FGS. A meta-analysis found a pooled sensitivity of $78 \%$ and specificity of $88 \%$ for CIN2+/high-grade squamous intraepithelial lesion detection by VIA as compared to

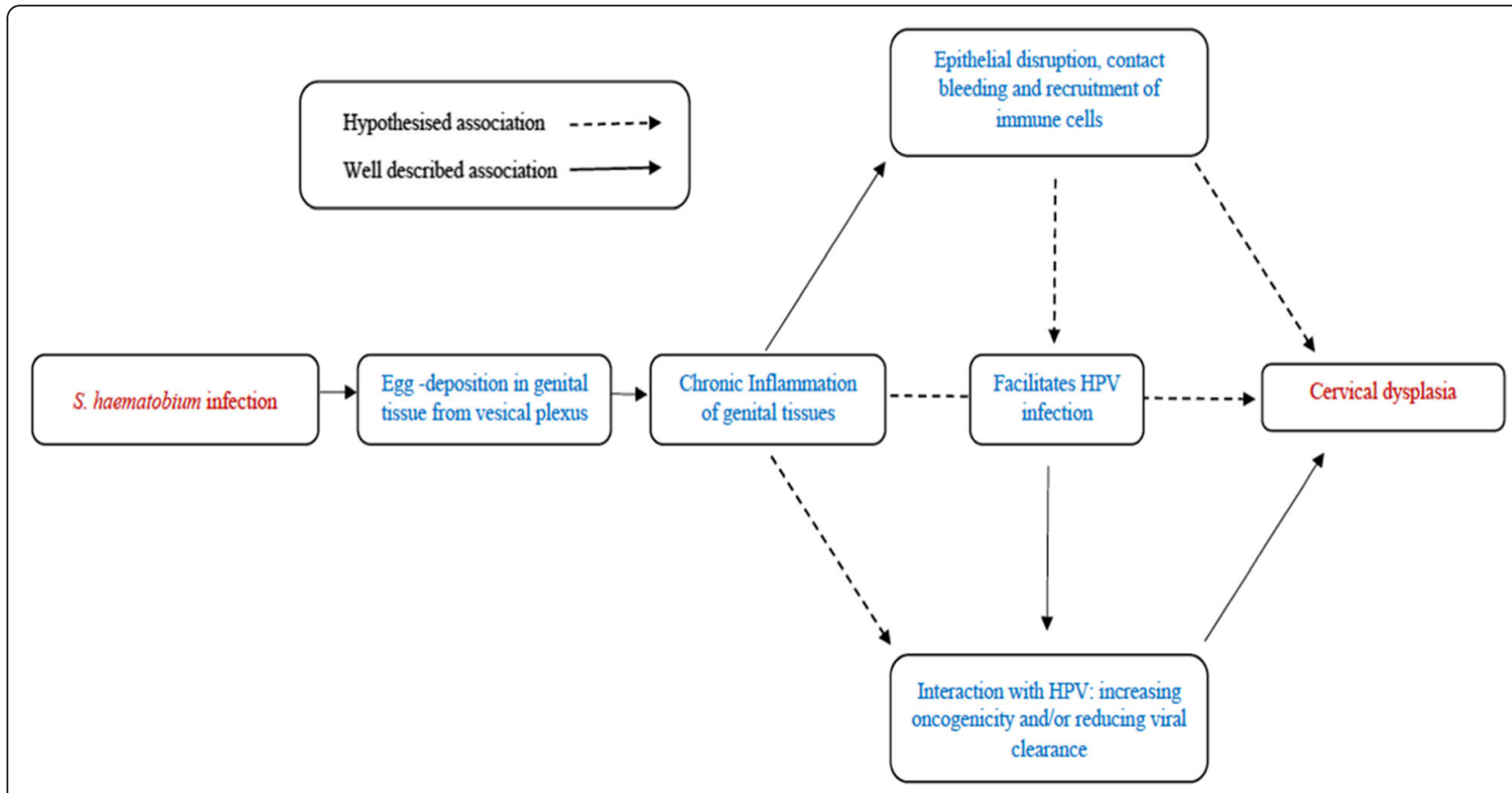

Fig. 3 Conceptual pathway highlighting possible mechanisms linking female genital schistosomiasis and cervical dysplasia 
colposcopy [37], and was preferable in terms of resources and availability [38]. In our cohort we found a low uptake of cervical cancer screening (44.9\%), which has previously been demonstrated in Zambia [39]. This may reflect known barriers to cervical cancer screening such as limited health education and stigma [40]. Indeed, a 2016 cross-sectional study in Lusaka, Zambia found that only $36.8 \%$ of participants had heard of cervical cancer and only $20.7 \%$ of women had ever attended screening [41]. VIA has been extensively used in Zambia and has been shown to be effective in reducing cervical cancer related mortality [42], and can be effectively scaled up to reach a higher proportion of the population [43] .

This study included young women aged $18-31$. There is a lack of evidence surrounding age of initiation for cervical screening, in part due to reduced cervical cancer incidence in women under 25 [4], lesion regression in younger women [44], and potential of harm with cervical interventions [45]. Zambian guidelines suggest screening initiation at 25 and WHO recommends screening HIVpositive women regardless of age [46]. Due to high HIV prevalence, all women presenting to Livingstone Central Hospital are offered VIA screening [27]. Including only younger women in this study may limit its generalisability and further investigation including older women may be required. Increased risk of cervical cancer in women with HIV-1 is well documented [47] however, this study was not powered to detect such an association. Our study did not collect data on previous cervical cancer screening, which is recommended for all HIV-1 positive women [48]. It is therefore possible that HIV positive women had previously been screened and treated.

Women in our study easily accessed the cervical cancer screening programme offered in the same clinic, illustrating how FGS diagnostics could be integrated into existing programmes. There is future potential for the diagnosis and treatment of two common and morbid gynaecological conditions at a single clinic visit. Given the cross-sectional study design, we cannot ascertain causality between FGS and cervical dysplasia. Lack of HPV testing, and absence of tissue biopsy to confirm VIA results also limit our conclusions. A longitudinal study is needed to investigate a temporal relationship between FGS, HPV, and cervical dysplasia across age groups and geographic locations. Mechanistic studies are also needed to elucidate the potential synergy between $S$. haematobium and HPV in cervical dysplasia. However, VIA remains a real-world diagnostic approach in low and middle income countries and is the recommended WHO screening modality in these settings [17].

In conclusion, this study shows an association between FGS, diagnosed by genital PCR, and VIA-positivity. Further research is needed to evaluate the association between FGS and cervical dysplasia and cervical cancer. If a causal link is established, FGS diagnosis and treatment may provide an additional opportunity to help reduce the burden of cervical cancer and achieve the WHO 2030 goal of cervical cancer elimination.

\section{Supplementary Information}

The online version contains supplementary material available at https://doi. org/10.1186/s12879-021-06380-5.

\section{Additional file 1.}

\section{Acknowledgements}

We would like to acknowledge the participants, and the efforts of field workers and midwives: N. Chola, E. Mwansa, M. Lukonga, R. Mwanza, M. Kantukaleza, J. Lungu, J. Mapani and M. Mudenda. We thank E. Kjetland for her image reviews. We gratefully acknowledge E. Briennen (LUMC) for performing the Schistosoma PCR, C. deDood (LUMC) and P. Hoekstra (LUMC) for performing the CAA analysis.

\section{Authors' contributions}

H. Rafferty: Conceptualisation, Methodology, Formal analysis, Investigation, Writing - Original Draft. A.S. Sturt: Methodology, Investigation, Data curation, Writing- Review \& Editing, Project administration. C.R. Phiri: Project administration, Writing- Review \& Editing. E.L. Webb: Formal analysis, Supervision, Data curation, Writing- Review \& Editing. M. Mudenda: Investigation, project administration. J. Mapani: Investigation, project administration. P.L.A.M. Corstjens: Investigation, Writing - Review \& Editing. G. J. Van Dam: Investigation, Writing - Review \& Editing. A. Schaap: Data curation H. Ayles: Resources, Writing - Review \& Editing. R. J. Hayes: Resources, Writing - Review \& Editing. L. Van Lieshout: Investigation, WritingReview \& Editing. I. Hansingo: Resources, Project administration, WritingReview \& Editing A.L. Bustinduy: Conceptualization, Methodology, Writing Review and Editing, Supervision, Project administration, Funding acquisition. The authors read and approved the final manuscript.

\section{Funding}

ALB is supported by a grant from the Wellcome Trust (205954/Z/17/Z) https://wellcome.ac.uk. ELW and $\mathrm{RH}$ received salary funding from MRC Grant Reference MR/K012126/1. This award is jointly funded by the UK Medical Research Council (MRC) and the UK Department for International Development (DFID) under the MRC/DFID Concordat agreement and is also part of the EDCTP2 program supported by the European Union. The funders had no role in study design, data collection and analysis, decision to publish, or preparation of the manuscript.

\section{Availability of data and materials}

Due to the sensitive nature of the data collected in the BILHIV study, data will be available upon request by contacting the study PI Dr. Amaya Bustinduy. The data will be available on LSHTM Data Compass. Data will available on request, which is advised by the LSHTM information management team. The data will be available by request on LSHTM Data Compass.

\section{Declarations}

Ethics and consent to participate

Informed consent was obtained from all study participants. Ethical approval was granted by LSHTM (reference 16,451) and University of Zambia Biomedical Research Ethics Committee (reference: 011-08-17). Livingstone Central Hospital Superintendent gave permission to conduct the study.

\section{Consent for publication}

Informed consent was obtained from all study participants for publication and dissemination of results. All authors gave consent for publication. 


\section{Author details}

'Department of Clinical Research, London School of Hygiene and Tropical Medicine, Keppel Street, London WC1E 7HT, UK. 'Zambart, Lusaka, Zambia. ${ }^{3}$ MRC International Statistics and Epidemiology Group, London School of Hygiene and Tropical Medicine, London, UK. ${ }^{4}$ Livingstone Central Hospital, Livingstone, Zambia. ${ }^{5}$ Department of Cell and Chemical Biology, Leiden University Medical Center, Leiden, The Netherlands. ${ }^{6}$ Department of Parasitology, Leiden University Medical Center, Leiden, The Netherlands.

\section{Received: 26 February 2021 Accepted: 27 May 2021}

Published online: 17 July 2021

\section{References}

1. Hotez PJ, Harrison W, Fenwick A, Bustinduy AL, Ducker C, Sabina Mbabazi P, et al. Female genital schistosomiasis and HIV/AIDS: reversing the neglect of girls and women. PLoS Negl Trop Dis. 2019;13(4):e0007025. https://doi.org/1 0.1371/journal.pntd.0007025.

2. Kjetland EF, Leutscher PD, Ndhlovu PD. A review of female genital schistosomiasis. Trends Parasitol. 2012;28:58-65.

3. Christinet V, Lazdins-Helds JK, Stothard JR, Reinhard-Rupp J. Female genital schistosomiasis (FGS): from case reports to a call for concerted action against this neglected gynaecological disease. Int J Parasitol. 2016;46(7):395404. https://doi.org/10.1016/j.ijpara.2016.02.006.

4. The Union International Cancer Control. New Global Cancer Data: GLOBOCAN 2018. Geneva: UICC; 2018. (September):1. Available from: https://www.uicc.org/new-global-cancer-data-globocan-2018

5. Jedy-Agba E, Joko WY, Liu B, et al. Trends in cervical cancer incidence in sub-Saharan Africa. Br J Cancer. 2020;123:148-54. https://doi.org/10.1038/ s41416-020-0831-9.

6. Africa WHO. Cervical cancer common amongst African women; 2018.

7. IARC. Schistosomes, Liver Flukes and Helicobacter pylori. In: Iarc Monogr Eval Carcinog Risks To Humans; 1994

8. World Health Organisation. A Global Strategy for elimination of cervical cancer. Geneva: Who; 2019.

9. Poggensee G, Kiwelu I, Weger V, Göppner D, Diedrich T, Krantz I, et al. Female genital schistosomiasis of the lower genital tract: prevalence and disease-associated morbidity in northern Tanzania. J Infect Dis. 2000;181(3): 1210-3. https://doi.org/10.1086/315345.

10. Poggensee G, Sahebali S, Van Marck E, Swai B, Krantz I, Feldmeier H. Diagnosis of genital cervical schistosomiasis: comparison of cytological, histopathological and parasitological examination. Am J Trop Med Hyg. 2001;65(3):233-6. https://doi.org/10.4269/ajtmh.2001.65.233.

11. Norseth HM, Ndhlovu PD, Kleppa E, Randrianasolo BS, Jourdan PM, Roald B, et al. The colposcopic atlas of schistosomiasis in the lower female genital tract based on studies in Malawi, Zimbabwe, Madagascar and South Africa. PLoS Negl Trop Dis . 2014;8(11):e3229. https://doi.org/10.1371/journal.pntd. 0003229 .

12. Sturt AS, Webb EL, Phiri CR, Mweene T, Chola N, van Dam GJ, Corstjens PLAM, Wessels E, Stothard JR, Hayes R, Ayles H, Hansingo I, van Lieshout L, Bustinduy AL. Genital selfsampling compared with cervicovaginal lavage for the diagnosis of female genital schistosomiasis in Zambian women: The BILHIV study. PLoS Negl Trop Dis. 2020;14(7):e0008337. https://doi.org/10.13 71/journal.pntd.0008337.

13. Kjetland EF, Ten Hove RJ, Gomo E, Midzi N, Gwanzura L, Mason P, et al. Schistosomiasis PCR in vaginal lavage as an indicator of genital Schistosoma haematobium infection in rural Zimbabwean women. Am J Trop Med Hyg. 2009;81(6):1050-5. https://doi.org/10.4269/ajtmh.2009.09-0081.

14. Phiri C, Sturt A, Webb E, Chola N, Hayes R, Shanaube K, et al. Acceptability and feasibility of genital self-sampling for the diagnosis of female genital schistosomiasis: a cross-sectional study in Zambia [version 1; peer review: awaiting peer review]. Wellcome Open Res. 2020;5:61. https://doi.org/10.12 688/wellcomeopenres.15482.2.

15. Poggensee G, Kiwelu I, Saria M, Richter J, Krantz I, Feldmeier H. Schistosomiasis of the lower reproductive tract without egg excretion in urine. Am J Trop Med Hyg. 1998;59(5):782-3. https://doi.org/10.4269/ajtmh.1 998.59.782.

16. Jenkins D. Histopathology and cytopathology of cervical cancer. Dis Markers. 2007;23(4):199-212. https://doi.org/10.1155/2007/874795.

17. WHO. Guidelines for screening and treatment of precancerous lesions for cervical cancer prevention. Geneva: WHO Guidel; 2013.
18. Sankaranarayanan R, Wesley R, Thara S, Dhakad N, Chandralekha B, Sebastian $P$, et al. Test characteristics of visual inspection with $4 \%$ acetic acid (VIA) and Lugol's iodine (VILI) in cervical cancer screening in Kerala, India. Int J Cancer. 2003;106(3):404-8. https://doi.org/10.1002/ijc.11245.

19. Mustafa RA, Santesso N, Khatib R, Mustafa AA, Wiercioch W, Kehar R, et al. Systematic reviews and meta-analyses of the accuracy of HPV tests, visual inspection with acetic acid, cytology, and colposcopy. Int J Gynecol Obstetr. 2016;132.

20. Gwavava C, Harrison NJT, Gwata DJ. TFZ. Incidence of Schistosomiasis in surgical biopsies: a review of 284 cases. Cent Afr J Med. 1984;30(12):241-5.

21. Youssef AF, Fayad MM, Shafeek MA. Bilharziasis of the cervix uteri. BJOG An Int J Obstet Gynaecol. 1970;77(9):847-51. https://doi.org/10.1111/j.1471-052 8.1970.tb04412x.

22. Kjetland EF, Ndhlovu PD, Mduluza T, Deschoolmeester V, Midzi N, Gomo E, et al. The effects of genital Schistosoma haematobium on human papillomavirus and the development of cervical neoplasia after five years in a Zimbabwean population. Eur J Gynaecol Oncol. 2010;31(2):169-73.

23. Pillay P, Van Lieshout L, Taylor M, Sebitloane M, Zulu SG, Kleppa E, et al. Cervical cytology as a diagnostic tool for female genital schistosomiasis: Correlation to cervical atypia and Schistosoma polymerase chain reaction. Cytojournal. 2016;13(1).

24. Hayes R, Donnell D, Floyd S, Mandla S, Bwalya J, Sabapathy K, et al. Effect of universal testing and treatment on HIV incidence - HPTN 071 (PopART). N Engl J Med. 2019;381(3):207-18. https://doi.org/10.1056/NEJMoa1814556.

25. World Health Organisation. Female genital schistosomiasis. A pocket atlas for clinical health-care professionals. Who/Htm/Ntd/20154. 2015.

26. Health ZM. Guidelines for the etiological and clinical management of sexually transmitted infections in Zambia; 2017.

27. UNAIDS. UNAIDS Country Factsheet: Zambia 2018. 2018.

28. Obeng BB, Aryeetey YA, De Dood CJ, Amoah AS, Larbi IA, Deelder AM, et al. Application of a circulating-cathodic-antigen (CCA) strip test and real-time PCR, in comparison with microscopy, for the detection of Schistosoma haematobium in urine samples from Ghana. Ann Trop Med Parasitol. 2008;102(7).

29. Pillay P, Taylor M, Zulu SG, Gundersen SG, Verweij JJ, Hoekstra P, et al. Realtime polymerase chain reaction for detection of Schistosoma DNA in smallvolume urine samples reflects focal distribution of urogenital schistosomiasis in primary school girls in KwaZulu Natal, South Africa. Am J Trop Med Hyg. 2014;90(3)

30. Corstjens PLAM, de Dood CJ, Knopp S, Clements MN, Ortu G, Umulisa I, et al. Circulating anodic antigen (CAA): a highly sensitive diagnostic biomarker to detect active schistosoma infections_-improvement and use during SCORE. Am J Trop Med Hyg. 2020;103(1_Suppl):50-7. https://doi. org/10.4269/ajtmh.19-0819.

31. STATA. STATA Glossary and Index Release 15. Stata - Manual Usuari. 2013.

32. Sturt AS, Webb EL, Francis SC, Hayes R, Bustinduy AL Beyond the barrier. female genital schistosomiasis as a potential risk factor for HN-1 acquisition. Acta Trop. 2020;209.

33. Scott ME, Shvetsov YB, Thompson PJ, Hernandez BY, Zhu X, Wilkens LR, et al. Cervical cytokines and clearance of incident human papillomavirus infection: Hawaii HPV cohort study. Int J Cancer. 2013;133(5).

34. Bais AG, Beckmann I, Ewing PC, Eijkemans MJC, Meijer CJLM, Snijders PJF, et al. Cytokine release in HR-HPV(+) women without and with cervical dysplasia (CIN II and III) or carcinoma, compared with HR-HPV(-) controls. Mediat Inflamm. 2007;2007:1-8. https://doi.org/10.1155/2007/24147.

35. Cohen PA, Jhingran A, Oaknin A, Denny L. Cervical cancer. Lancet. 2019;393.

36. Kjetland EF, Ndhlovu PD, Mduluza T, Gomo E, Gwanzura L, Mason PR, et al. Simple clinical manifestations of genital Schistosoma haematobium infection in rural Zimbabwean women. Am J Trop Med Hyg. 2005;72(3):311-9. https://doi.org/10.4269/ajtmh.2005.72.311.

37. Catarino $R$, Schäfer $S$, Vassilakos $P$, Petignat $P$, Arbyn M. Accuracy of combinations of visual inspection using acetic acid or lugol iodine to detect cervical precancer: a meta-analysis. BJOG. 2018.

38. De Vuyst H, Claeys P, Njiru S, Muchiri L, Steyaert S, De Sutter P, et al. Comparison of pap smear, visual inspection with acetic acid, human papillomavirus DNA-PCR testing and cervicography. Int J Gynecol Obstet. 2005

39. Siziya S, Kabalika MB, Mulenga D, Mazaba ML. Acceptance of cervical cancer screening and its correlates among women of a peri-urban high-density residential area in Ndola, Zambia. Int J MCH AIDS. 2018.

40. Pierz AJ, Randall TC, Castle PE, Adedimeji A, Ingabire C, Kubwimana G, et al. A scoping review: Facilitators and barriers of cervical cancer screening and early diagnosis of breast cancer in Sub-Saharan African health settings. Gynecol Oncol Rep. 2020;33. 
41. Nyambe A, Kampen JK, Baboo SK, Van Hal G. Knowledge, attitudes and practices of cervical cancer prevention among Zambian women and men BMC Public Health. 2019.

42. Parham GP, Mwanahamuntu MH, Sahasrabuddhe W, Westfall AO, King KE, Chibwesha C, et al. Implementation of cervical cancer prevention services for HIV-infected women in Zambia: Measuring program effectiveness. HIV Ther. 2010;4(6).

43. Parham GP, Mwanahamuntu MH, Kapambwe S, Muwonge R, Bateman AC, Blevins $\mathrm{M}$, et al. Population-level scale-up of cervical cancer prevention services in a low-resource setting: development, implementation, and evaluation of the cervical cancer prevention program in Zambia. PLoS One. 2015;10(4):e0122169. https://doi.org/10.1371/journal.pone.0122169.

44. Tainio K, Athanasiou A, Tikkinen KAO, Aaltonen R, Cárdenas J. Hernándes, et al. Clinical course of untreated cervical intraepithelial neoplasia grade 2 under active surveillance: Systematic review and meta-analysis. BMJ. 2018.

45. Kyrgiou M, Koliopoulos G, Martin-Hirsch P, Arbyn M, Prendiville W, Paraskevaidis E. Obstetric outcomes after conservative treatment for intraepithelial or early invasive cervical lesions: systematic review and metaanalysis. Lancet. 2006;367(9509):489-98. https://doi.org/10.1016/S0140-673 6(06)68181-6.

46. WHO. WHO guidelines: essential prevention and care interventions for adults and adolescents living with HIV in resource limited settings. 2008.

47. Stelzle D, Tanaka LF, Lee KK, Ibrahim Khalil A, Baussano I, Shah ASV, et al. Estimates of the global burden of cervical cancer associated with HIV. Lancet Glob Health. 2021;9(2).

48. WHO. Accelerate Cervical Cancer Elimination 2020 [cited 2021 Apr 28]. Available from: https://www.who.int/reproductivehealth/publications/ screening-cervical-pre-cancer-lesions-women-with-hiv/en/

\section{Publisher's Note}

Springer Nature remains neutral with regard to jurisdictional claims in published maps and institutional affiliations.

Ready to submit your research? Choose BMC and benefit from:

- fast, convenient online submission

- thorough peer review by experienced researchers in your field

- rapid publication on acceptance

- support for research data, including large and complex data types

- gold Open Access which fosters wider collaboration and increased citations

- maximum visibility for your research: over $100 \mathrm{M}$ website views per year

At $\mathrm{BMC}$, research is always in progress.

Learn more biomedcentral.com/submissions 